\title{
ASSOCIATION BETWEEN PULSE INDEX AND METABOLIC SYNDROME IN INDIVIDUALS WITH TYPE 2 DIABETES MELLITUS: OUTCOME OF A TWELVE-WEEKS THERAPEUTIC EXERCISE PROGRAMME
}

\author{
Journal website at; \\ http://mrtbjournal.org/index.php/njmr/issue/current/showToc \\ ${ }^{1}$ A F ADENIYI, ${ }^{2}$ AO SANYA, ${ }^{3}$ AA FASANMADE, ${ }^{4}$ B TIJJANI, ${ }^{4}$ AE ULOKO. \\ 'Department of Physiotherapy, Faculty of Medicine, Bayero University, Kano, Nigeria. \\ ${ }^{2}$ Department of Physiotherapy, College of Medicine, University of Ibadan, Nigeria \\ ${ }^{3}$ Department of Medicine, University College Hospital, Ibadan, Nigeria \\ ${ }^{4}$ Department of Medicine, Aminu Kano Teaching Hospital, Kano, Nigeria. \\ Correspondence to: \\ Adeniyi, A. F. \\ E-Mail: adeniyifatai@yahoo.co.uk \\ Tel: 08065549323
}

\begin{abstract}
SUMMARY
Background and Objective: Metabolic syndrome (MS) is an entity with clustering of cardiovascular risk factors and is associated with Type 2 Diabetes Mellitus (T2DM). Lowlevel cardiovascular fitness is also associated with risk of T2DM. An association between Pulse Index (PI) and MS requires further description. This study sought to determine the association between PI and components of MS.

Methods: Seventy-seven participants/subjects aged $48.6 \pm 6.52$ years with $T 2 D M$ were enrolled into the study at Aminu-Kano Teaching Hospital, Kano, Nigeria. PI and components of MS including Fasting Blood Glucose (FBG), Glycosylated Haemoglobin (HBA 1c), High-Density Lipoprotein (HDL-CHOL), Triglycerides (TRIG.), Blood Pressure (BP) and obesity were assessed before and after twelve-week therapeutic exercises.

Results: Inverse correlations were obtained for PI and each of FBG $(r=-0.45)$, HBAlc $(r=-0.52)$, TRIG $(r=-0.26)$, $\mathrm{BP}(\mathrm{r}=-0.43 /-0.32)$, Waist Circumference $(\mathrm{r}=-0.53)$, BMI ( $\mathrm{r}$ $=-0.79)$, blood pressure $(r=-0.43 /-0.32)$ except HDL-CHOL $(r=0.67),(P<0.05$ for all the subjects/participants $)$.

Conclusions: Low-levels of PI were associated with poor glycaemia, hypertension, obesity and dyslipidaemia. Therapeutic exercises aimed at improving cardiovascular fitness may have significant improvement on MS, which in turn aids the prevention of both T2DM and cardiovascular diseases.
\end{abstract}

Keywords: Type 2 Diabetes Mellitus, Cardiovascular fitness, aerobic exercises, Pulse Index

\section{INTRODUCTION}

There is no doubt that diabetes mellitus is becoming an increasingly important public health problem in all countries. According to Dyek et al (1998), this appears largely due to changes in diet and activity levels associated with a shift away from traditional lifestyles. As the developing world urbanizes and becomes more affluent, so the incidence of type 2 diabetes mellitus rises (Price, 2004). This has brought up an increase in worldwide prevalence of diabetes so much that it has become a common problem in many ethnic groups that previously were hardly affected (Warren, 2002).

In Nigeria the prevalence ranges from $1.6 \%$ to $5 \%$, depending on the locality, and up to $10 \%$ for the adult population (Msheila, 2004). In South Africa, prevalence rates for diabetes mellitus are around $4.5 \%$ in whites, $15 \%$ in the Indian population and approximately $6-10 \%$ in the blacks and type 2 diabetes mellitus accounts for $90 \%$ of the total number as in most diabetic populations (Price, 2004). Vanhala (1999) stated that, sedentary lifestyles and lack of physical exercise pose more threat to diabetes mellitus pathology. This according to (Vanhala, 1999) results in an increased occurrence of overweight in childhood that may be the first sign of insulin resistance and future metabolic syndrome.

The term "metabolic syndrome" refers to a clustering of specific cardiovascular disease (CVD) risk factors whose underlying pathophysiology is thought to be related to insulin resistance (Kahn et al, 2005). It is an occurrence of disturbed glucose and insulin metabolism, overweight and abdominal fat distribution, mild dyslipidemia, and 
hypertension; and is associated with subsequent development of type 2 diabetes mellitus (Lakka et al, 2002; Hu et al, 2004). The Adult Treatment Panel III (2001) defined metabolic syndrome as when 3 or more of the following 5 risk factors are present: (1) systolic blood pressure of $130 \mathrm{~mm} \mathrm{Hg}$ or higher and/or diastolic blood pressure of $85 \mathrm{~mm} \mathrm{Hg}$ or higher; (2) high-density lipoprotein cholesterol levels of less than $40 \mathrm{mg} / \mathrm{dl}(<1.03$ $\mathrm{mmol} / \mathrm{L})$ in men and less than $50 \mathrm{mg} / \mathrm{dl}(<1.29 \mathrm{mmol} / \mathrm{L})$ in women; (3) triglyceride levels of $150 \mathrm{mg} / \mathrm{dl}$ or higher ( 1.7 $\mathrm{mmol} / \mathrm{l})$; (4) glycated hemoglobin level higher than $6.1 \%$ or fasting plasma glucose levels of $110 \mathrm{mg} / \mathrm{dl}$ or higher $(6.1 \mathrm{mmol} / \mathrm{l})$, and (5) waist circumference greater than 94 $\mathrm{cm}$ in men and greater than $80 \mathrm{~cm}$ in women.

According to WHO (2004), CVD is responsible for between $50 \%$ and $80 \%$ of deaths in people with diabetes. Over the course of the past half century, metabolic disease has emerged as the most prevalent cause of death in industrialized nations (Centers for Disease Control and Prevention, 1996).

When an individual is identified as having the metabolic syndrome, it is not always clear what should be the treatment of choice or the goals of therapy (Khan et al, 2005). Khan et al (2005) further stated that, no studies have examined the value of tailoring the treatment algorithm to the particular combination of criteria that result in the diagnosis of the syndrome. It is observed that studies abound on the application of a variety of therapeutic exercises in enhancing cardiovascular fitness of individuals with T2DM (Brandenburg et al, 1999; Bauman and Owen, 1999; Sigal et al, 2004 and ADA, 2006). It is however uncertain if combination of these exercises will have beneficial effect on their Metabolic Syndrome (MS). This study therefore sought to investigate the relationship between PI and MS and to investigate whether exercises tailored towards improvement of cardiovascular fitness will also improve on the components of MS.

\section{MATERIALSAND METHODS}

The participants or subjects for this study were 77 volunteers with type 2 Diabetes Mellitus attending the Specialty (Diabetic) Clinic of the Aminu Kano Teaching Hospital, (AKTH), Kano. They were between the ages of 30 and 64 years and were not previously engaged in any therapeutic exercises. Their physicians referred them for the exercises following satisfactory medical examinations.

The research was a prospective design that included pre-test, intervention and post-test phases and participants were recruited as they became available. The venue of this research was the out-patient Physiotherapy Clinic of AKTH, Kano. Ethical approval was sought and obtained from the Ethical Committee on Research of the AKTH, Kano. The experimental procedure of the research were explained to the participants before the commencement of the study.

The components of the metabolic syndrome assessed included glucose regulation, arterial blood pressure, plasma triglycerides, high density lipoprotein cholesterol and obesity while pulse index was assessed using the Harvard Step Test. This was followed by the twelve weeks of therapeutic exercise sessions in which the participants received outlined therapeutic exercises (aerobic and strengthening) in addition to drug and/or diet regimen that might have been prescribed for them earlier. The same data were also obtained and recorded at the end of the $12^{\text {ih }}$ week making up the therapeutic exercise session.

\section{Data Collection}

The following data on participants were assessed and recolded:

1. Pulse Index: This was obtained from the Harvard Step Test (Magee, 1992) and used as the assessment of cardiovascular component of fitness of the participants. The Harvard step test according to Magee (1992) is one of the most common and simple general cardiovascular fitness tests done for physical fitness profile. To set up the test, a $0.45 \mathrm{~m}$ platform was used. The participant was instructed to step one foot after another onto the platform at the rate of about 30 steps/min (a metronome was used for cadence). The participant was made to step for 3.5 minutes at a pace of 2 seconds/step then step as fast as possible for 30 seconds (total time for the test was 4 minutes). The participant immediately sat down in a chair and relaxed for three minutes while the pulse was determined. The pulse was taken at 30,60,120 and 180 seconds after the exercise. The index formula for pulse is:

Index $=$ Duration of exercise (in seconds) X 100

$2 \mathrm{X}$ the sum of any three pulse counts (Magee, 1992; Trevino et al, 1999)

The higher the pulse index, the better the person's fitness. If the index was less than 65 the participant may be declared not physically fit (Magee, 1992).

2. Body Mass Index (BMI); Waist Circumference $(W C$ ): These were measured as part of the component of metabolic syndrome. The procedure were as reported in previous studies (Hall et al, 1989; Haslett et al, 1999; Wilmore and Costill, 2004).

3. Waist Hip Ratio: As described by Wilmore and Costill (2004).

4. Fasting Blood Glucose (FBG), Glycosylated haemoglobin $(H B A I C)$ and Lipid profile analysis: These tests were carried out at the Chemical Pathology Laboratory of AKTH. The FBG, High Density Lipoprotein cholesterol (HDL-CHOL) and Triglycerides (TRIG) were measured in mmol/l, while HBA lc was measured in percentage (Tattersall and Gale, 1990).

5. Systolic anddiastolic blood pressures: These were measured using mercury sphygmomanometer. The cuff of the sphygmomanometer was placed around 
the participant's bare arm just above the ante-cubital space. Ear tips are placed in the ears and pointing forward; brachial artery was palpated at the antecubital space and bell of stethoscope was placed over it. The valve of the sphygmomanometer was closed and bulb was pumped until mercury column was about $40 \mathrm{mmHg}$ over anticipated systolic pressure. Air was let out by turning the valve slowly and the Korotkoff sounds were noted (Kemp et al, 1990).

\section{Therapeutic Exercises}

The participants were allowed to rest in a sitting position for at least 10 minutes before the commencement of the exercise training (Sanya and Akanji, 1999). The total duration of exercise per session was between 50 and 65 minutes (Wilson et al, 1981). This was made up of ten minutes of warm-up and cool-down exercises of five minutes each. Each participant went through the exercise for three times in a week, for 12 weeks, making 36 sessions.

The therapeutic exercises were divided into four regimens comprising aerobic, strengthening and joint mobilization exercises, aimed at improving cardiovascular fitness (Brandenburg et al, 1999; Bauman and Owen, 1999; Sigal et al, 2004):

Exercise regimen I: The participants were asked to pedal a bicycle ergometer at an intensity of $60 \%$ of heart rate reserve (HRR); i.e. [0.6 X (Heart Rate max $_{\text {meart Rate }}$, Hess + Heart Rate $_{\text {rest }}$ ] for about 20 minutes (Wilson et al, 1981) with five minutes break after 10 minutes (Wilson et al, 1981; Cuff et al, 2003).

Exercise Regimen II: These included two rounds of brisk walking with full arm swings up and down the length of the gymnasium (about ten meters long) (Sigal et al, 2004) till volitional exhaustion. Minimum of three minutes rest was observed between the two laps by the participants. Exercise Regimen III: Free active movements of the joints of the shoulder, elbow, wrists, fingers, hip, knees and ankle were carried out to as full range as possible (Sanya, 1997; Goldsmith et al, 2002). Participants were encouraged to mobilize the joints in the movement planes as full as possible making ten repetitions in each.

Exercise Regimen IV: Strengthening exercises were carried out in this session. $60 \%$ of the individual's one repetition maximum (1RM) was determined and used to strengthen each group of muscles. Participants were asked to perform two sets of ten repetitions each with recovery time of two minutes between sets (Brandon et al, 2003). This resistance regimen was done for flexors and extensors of the knees and elbows (Lycholat, 1990; Brandon et al, 2003). The participants also carried out strengthening exercises for both hands using lawn tennis balls. They were encouraged to squeeze the balls as strongly as they could, making ten repetitions each. A set of ten repetitions each of back curls and bilatcral straight leg raisings were also carried out by the participants at speed comfortable to them.
Data were analyzed using: Descriptive statistics of Mean, mode, range, and standard deviation; and Inferential Statistics of Pearson's moment correlation coefficient (r), to reveal associations between the PI and the components of the MS. Coefficient of Determination $\left(r^{2}\right)$ were further calculated from the Pearson's correlation coefficient (r). Significance level was set at 0.05 level of alpha.

\section{RESULTS}

The mean age of the participants was $48.6 \pm 6.52$. They were made up of 29 males $(37.66 \%)$ and 48 females $(62.34 \%)$. The descriptive statistics of selected components of the Metabolic Syndrome (MS) of the participants at baseline are as shown in Table 1 . The mean BMI was $34.84 \pm 7.76 \mathrm{~kg} / \mathrm{m}^{2}$ while the mean Waist Circumference (WC) for males was $103.90 \pm 13.09 \mathrm{~cm}$. The mean of FBG was $8.62 \pm 2.77 \mathrm{mmol} / \mathrm{l}$ and that of Glycosylated Haemoglobin (HBAl ) was $11.21 \%$ at baseline. Table 1 also shows the baseline levels of lipid profile analysis of the participants. The mean High Density Lipoprotein (HDL-CHOL) for males, and Triglycerides (TRIG) were $0.71 \pm 0.18 \mathrm{mmol} / \mathrm{l}, 1.86 \pm 0.29 \mathrm{mmol} / \mathrm{l}$ respectively; while Pulse Index (PI) was 55.65 at baseline

Table 1: Descriptive statistics of PI and selected components of the MS of participants at baseline

\begin{tabular}{lcccc}
\hline Variable & Mean \pm SD & Mininum & Maximum & 95\% Cl \\
\hline $\begin{array}{l}\text { BMI } \\
\left(\mathrm{Kg} / \mathrm{m}^{2}\right)\end{array}$ & $34.84 \pm 7.76$ & 22.50 & 65.30 & $32.45-37.23$ \\
$\begin{array}{l}\text { WC (cm) } \\
\text { (males) }\end{array}$ & $103.90 \pm 13.09$ & 78.00 & 139.00 & $99.87-107.93$ \\
(females) & $92.53 \pm 8.96$ & 76.50 & 128.30 & $74.26-101.32$ \\
WHR & & & & \\
(males) & $0.96 \pm 0.04$ & 0.87 & 1.03 & $0.95-0.97$ \\
(females) & $0.90 \pm 0.02$ & 0.82 & 0.98 & $0.79-0.95$ \\
FBG & & & & \\
(mmol/l) & $8.62 \pm 2.77$ & 3.20 & 22.00 & $9.47-11.92$ \\
HBAl & & & & \\
(\%) & $11.21 \pm 2.71$ & 7.20 & 13.60 & $9.55-10.61$ \\
HDL (mmol/l) & & & \\
(males) & $0.71 \pm 0.18$ & 0.62 & 1.60 & $0.62-0.86$ \\
(females) & $0.81 \pm 0.19$ & 0.76 & 1.34 & $0.79-0.1 .18$ \\
TRIG & & & & \\
(mmol/l) & $1.86 \pm 0.29$ & 1.10 & 2.40 & $1.69-2.12$ \\
SBP & & & & \\
(mmHg) & $145.30 \pm 19.05$ & 140 & 195 & $145-187$ \\
$\begin{array}{l}\text { DBP } \\
\text { (mmHg) }\end{array}$ & $96.86 \pm 8.16$ & 93 & 110 & $94-107$ \\
PI & $55.65 \pm 4.43$ & 51.34 & 62.15 & $52.4-57.1$ \\
\hline
\end{tabular}

\section{Abbreviations}

BMI - Body Mass Index

WC - Waist Circumference

WHR - Waist-Hip-Ratio

FBG - Fasting Blood Glucose

$\mathrm{HBAl}_{\mathrm{c}}$ - Glycosylated Haemoglobin

HDL - High Density Lipoprotein

TRIG - Triglycerides

SBP- Systolic Blood Pressure

DBP - Diastolic Blood Pressure

PI - Pulse Index

$\mathrm{CI}$ - Confidence Interval 
Significant changes were obtained in PI and all the components of MS when post exercise levels were compared with their pre-exercise levels $(\mathrm{P}<0.05)$ for all (Table 2). Inverse and weak, but significant correlations were observed for the associations between PI and the components of $\mathrm{Ms}$ at baseline $(\mathrm{P}<0.05$ for all the components) except the HDL-CHOL that was positive (Table 3). Table 3 also contains the Coefficient of Determination (CD), which indicates that a change in the component of MS equal to the percentage of the corresponding CD value was due to an increase in the PI level. Most of the CDs increased in value by the end of the twelfth week. Highest increases in CD were seen in TRIG HDL-CHOL., SBP and DBP.

Table 2: Pre and post twelve-week changes in PI and selected components of the MS

\begin{tabular}{lccl}
\hline Variable & $\begin{array}{l}\text { Mean Difference } \\
\text { (Pre-Post) }\end{array}$ & Paired t & P- Value \\
\hline BMI $\left(\mathrm{Kg} / \mathrm{m}^{2}\right)$ & 7.09 & 11.85 & $<0.05$ \\
WC $(\mathrm{cm})$ & 12.86 & 13.61 & $<0.05$ \\
WHR & 0.10 & 13.08 & $<0.05$ \\
FBG $(\mathrm{mmol} / \mathrm{l})$ & 5.51 & 10.52 & $<0.05$ \\
HBA ${ }_{\mathrm{c}}(\%)$ & 2.47 & 4.65 & $<0.05$ \\
HDL $(\mathrm{mmol} / \mathrm{l})$ & -0.87 & -10.60 & $<0.05$ \\
TRIG $(\mathrm{mmol} / \mathrm{l})$ & 0.75 & 5.61 & $<0.05$ \\
SBP mmHg & 13.09 & 5.41 & $<0.05$ \\
DBP mmHg & 16.86 & 5.12 & $<0.05$ \\
PI & -8.09 & -11.78 & $<0.05$ \\
\hline
\end{tabular}

Table 3: Correlations between PI and components of MS at pre and post twelve week of therapeutic exercises

\begin{tabular}{|c|c|c|c|c|}
\hline Correlations & $\begin{array}{l}\text { Pearson's } r \\
\text { (Baseline) }\end{array}$ & $\begin{array}{l}\mathbf{r}^{2}=\mathrm{CD} \\
\text { (Baseline) }\end{array}$ & $\begin{array}{l}r^{2}=C D \\
\left(12^{\text {th }} \text { week }\right.\end{array}$ & $\begin{array}{l}\text { P.Value } \\
\text { k) }\end{array}$ \\
\hline PI Vs FBG & -0.45 & 0.20 & 0.27 & $<0.05$ \\
\hline PI Vs HBAlc & -0.52 & 0.27 & 0.29 & $<0.05$ \\
\hline PI Vs TRIG & -0.26 & 0.06 & 0.17 & $<0.05$ \\
\hline PI Vs HDL-CH & HOL. 0.57 & 0.32 & 0.66 & $<0.05$ \\
\hline PI Vs BMI & -0.59 & 0.34 & 0.49 & $<0.05$ \\
\hline PI Vs WC & -0.53 & 0.28 & 0.44 & $<0.05$ \\
\hline PI Vs WHR & -0.48 & 0.23 & 0.27 & $<0.05$ \\
\hline PI Vs SBP & -0.43 & 0.18 & 0.45 & $<0.05$ \\
\hline PI Vs DBP & -0.32 & 0.10 & 0.37 & $<0.05$ \\
\hline
\end{tabular}

$\mathbf{r}^{2}=$ Coefficient of Determination (CD)

\section{DISCUSSION}

Impaired glycaemic control, dyslipidaemia, hypertension and obesity observed at baseline qualified the participants to be described as having a Metabolic synarome (MIS). The presence of these components of MS in persons with Type 2 Diabetes Mellitus has been documented (WHO, 1999; Mayes 2000; WHO 2004; ADA 2006; Khunti and Davies, 2006). At baseline, the participants in this study had a low Pulse Index (PI) that indicated that they had low cardiovascular fitness. This could be as a result of sedentary lifestyle, high blood glucose, and other components of MS that constituted risk factors for cardiovascular disorders. Regensteiner et al (2005) reported that even in the absence of apparent cardiovascular disease, individuals with T2DM have an impaired ability to carry out maximal exercise, indicating poor fitness and the impairment is correlated with insulin resistance.

Significant improvement observed in the participants after the period of twelve weeks could be largely accounted for by the inclusion of therapeutic exercises in their line of management. Regular physical activities have been found to have favourable impact on risk factors of ischemic heart disease and diabetes mellitus such as obesity, hypertension, dyslipidaemia, insulin resistance and others (Syacinova et al, 2003). The Coefficient of Determination (CD) for PI and FBG was found to have increased at the end of the twelfth week, indicating that about one third of the changes that had occurred in the FBG were due to the changes that occurred in cardiovascular fitness following the period of therapeutic exercises. This also means that the same therapeutic exercise that increased cardiovascular fitness had reduced the FBG (inverse correlations). Nishida et al (2001) reported that mild endurance exercise, (a component of this study), improves glucose effectiveness which is the ability of hyperglycaemia to promote glucose disposal in six weeks. Holten (2004) on the other hand pointed out that strength training (which was also a component of this study) increases insulin action in skeletal muscles. In a slight upgrade of the previous studies, this study combined the effect of both aerobic and strengthening exercises, and this could have been responsible for the benefits achieved in this study. For instance, in an exercise study carried out on postmenopausal women with Type 2 Diabetes Mellitus (T2DM) by Cuff et al (2003) it was revealed that a combination of aerobic and strengthening exercises for a period of sixteen weeks yielded enhanced glucose disposal.

The CD of PI and each of TRIG and HDL-CHOL were noticed to have more than doubled at the end of twelve week. This indicates that increase in PI brought about by the therapeutic exercise also increased the HDLCHOL (positive correlation) and reduced TRIG (inverse correlation). It can be deduced that more than half of the changes that occurred in HDL-CHOL was due to the increase in cardiovascular fitness brought about by the therapeutic exercise carried out. HDL-CHOL has been reported to increase following period of exercises, according to Mayes (2000). Kiens (1997) and Syancinova et al (2003) also documented the effect of therapeutic exercise in lowering LDL cholesterol, TCHO and TRIG levels. In the case of PI and BMI, the CD increased by about a half of the pre-exercise levels at the end of twelve weeks of exercises. This indicates that close to half of the 
reduction in BMI obtained in the participants at the end of the exercise programme was due to increase in cardiovascular fitness indicated by PI. Liao et al (2002) had reported significant reductions in percent body fat, BMI and skin fold thickness of these subjects when taken through diet therapy in addition to one hour endurance exercises, three times a week. Ibanez et al (2005) also claimed that sixteen weeks of two sessions per week of progressive resistance training, without a concomitant weight loss diet, significantly improves insulin sensitivity and fasting glycaemia and decreases abdominal fat in older men with type 2 diabetes. The CD of PI and both systolic and diastolic blood pressures more than doubled the preexercise levels at the end of twelve weeks indicating that close to half of the improvement in blood pressure of the participants was due to increase in cardiovascular fitness (PI) brought about by the therapeutic exercises they went through. Reports of Roberts and Ketayian (2003) have documented the effects of physical exercises on blood pressures. Tan et al (2005) also documented that global risk reduction strategies such as dietary restrictions and increased physical activity will help target treatment at hyperglycaemia, hypertension and dyslipidaemia.

\section{CONCLUSION}

It is observed from this study that poor cardiovascular fitness indicated by low Pulse Index (PI) level is associated with Metabolic Syndrome (MS). Increased levels of PI after a twelve-week therapeutic exercise was however associated with raised HDL-CHOL. The outcome of this study therefore revealed that therapeutic exercises usually prescribed in order to improve cardiovascular fitness can also be successfully utilized to improve on the MS of individuals with Type 2 Diabetes Mellitus. It is therefore recommended that before or alongside initiating pharmacological treatment, physical activities in the form of therapeutic exercises should be recommended to improve cardiovascular fitness and reduce burden of metabolic syndrome.

\section{REFERENCES}

- Adulı Treatment Panel III. (2001): Executive Summary of The Third Report of The National Cholesterol Education Program (NCEP) Expert Panel on Detection, Evaluation, and Treatment of High Blood Cholesterol ln Adults. Journal of American Medical Association 285: 2486 - 2497.

- American Diabetes Association. (2006). Summary of revisions for the 2006 clinical practice recommendations. Diabetes Care. 29: S3.

- Bauman A and Owen N (1999). Physical activity of adult Australians: epidemiological evidence and potential strategies for health gain. Journal of Science and Medicine in Sport. 2(1): $30-41$.

- Brandenburg SL, Reusch JE, Bauer TA, Jeffers BW, Hiatt WR and Kegensteiner JG (1999). Ettects of exercise Iraining on oxygen uptake: kinetic response to women with type 2 diabetes. Diabetes Care. 22(10): 1640 - 1646.
- Brandon LJ, Gaasch DA, Boyette LW and Lloyd AM. (2003). Effects of long-term resistive Training on mobility and strength in older adults with diabetes. Jounal of the Gerontology Series A: Biological Sciences and Medical Sciences 58(8): M740 - M745.

- Centers for Disease Control and Prevention (1996): Surgcon General's report on physical activity and health Joumal of American Medical Association 276: 522 - 529.

- Cuff DJ, Meneily GS, Martin A, lgnaszewski A, Tildesicy HD and Frohlick JJ (2003). Effective exercise modality to reduce insulin resistance in women with Type 11 Diabctes Diabetes Care. 26: 2977 - 2982.

- Dyek RF, Sheppard MS, Cassidy H, Chad K,Tan I and VanVliel SH (1998). Preventing non insulin dependent diabetes mellitus among aboriginal people: is exercise the Answer? International Journal of Circumpolar Heath. 57(suppl 1): $375-378$.

- Goldsmith JR, Lidtke RH and Shott S (2002). The effects of range of motion therapy on The plantar pressurcs of patients with diabctes mellitus. Journal of the American Podiatric Medical association. 92(9): 483 - 490.

- Hall JG, Froster-Iskenius VG and Allanson JE (1989). Handbook of normal physiological Measurements. (1"Ed.). Oxford Publications. New York; $78-79$.

- Haslett C, Chilvers ER, Hunter JAA and Boon NA (1999). Davidson's Principles and Practice of Medicine. (18"l Ed.). Churchill Livingstone. New York; 471 - 509.

- Holten MK, Zacho M, Gaster M, Juel C, Wojtaszewski JFP and Dela F (2004): Strength training incrcases insulinmediated glucose uptake, GLUT 4 content, and insulin signaling in skeletal muscles in patients with Type 2 diabetes. Diabetes Care. 29: $543-548$.

- Hu G, Qiaon Q, Tuomilehto J, Balkau B, Borch-Johnsen K, Pyorala K. (2004): Prevalence of the Metabolic Syndrome and Its Relation to All-Cause and Cardiovascular Mortality in Nondiabetic European Men and Women Archives of Internal Medicine.164: 1066 - 1076.

- Ibañez J, lzquierdo M, Argüelles I, Forga L, Larrión JL, García-Unciti M, Idoate F. and Gorostiaga, E.M. (2005). Twice-weekly progressive resistance training decreases abdominal fat and improves insulin sensilivity in older men with Type 2 diabetes Diabetes Care 28: 662 - 667 .

- Kahn, R., Buse, J. Ferrannini, E. and Stern, M. (2005): The Metabolic Syndrome: Time for a Critical Appraisal: Joint statement from the American Diabeles Associalion and the European Association for the Study of Diabetes. Diabetes Care 28: $2289-2304$.

- Kemp BB, Pilliter A and Brown P (1990). Fundamentals of Nursing: A Framework for Practice. (2nd Ed.). Scolt and Company. London; 584 - 598.

- Khunti K and Davies M (2006). Metabolic syndrome independently raises cardiovascular risk and should be picked up in primary care. British Medical Joumal West Africa Edition. 9(1): 20-21.

- Kiens B (199/). Etrect of endurance training on ratly acius metabolism in local adaptations. Medicine and Science in Sporl and Exercise. 29: 640-643. 
- Lakka HM, Laaksonen DE, Lakka TA, NiskanenLK., Kumpusalo E, Tuomilehto J, Salonen JT (2002): The Metabolic Syndrome and Total and Cardiovascular Disease Mortality in Middle-aged Men Journal of American Medical Association 288: $2709-2716$.

- Liao D, Asberry PJ, Shofer JB, Callahan H, Matthys C, Boyko EJ, Leonetti D, Kahn SE, Austin M, Newell L, Schwarts RS. and Fujimoto WY. (2002). Improvement of BMI, body composition and body fat distribution with lifestyle modification in Japanese-Americans with impared glucose tolerance. Diabetes Care. 25(9): 1504-1510.

- Lycholat T (1990). The Complete Book of Resistance Training. Crowood Press. London; 31 - 35.

- Magee DJ (1992). Orthopaedics Physical Assessment. (3 Ed.). WB. Saunders Company. Philadelphia; 758 - 779.

- Mayes PA (2000). Lipid transport and storage. In: Harper's
Biochemistry. (eds): Murray, R.K., Granner, D.K., Mayes, P.A. and Rodwell, V.W. (25 ${ }^{\text {in }}$ Ed.). Lange Medical Books. New York; 268 - 284

- Mshelia DS. (2004). Is diabetes mellitus a forgotten evil? Africa Health. 26(5): 3

- Nishida Y, Higaki Y, Tokuyama K, Fujimi K, Kyonaga A, Shindo M, Sato $Y$ and Tanaka, H. (2001). Effects of mild exercise training on glucose effectiveness in healthy men. Diabetes Care. 24: 1008 - 1013

- Price C (2004). Epidemiological trends and difficulties of diabetic care delivery on the Africa Continent- A South African perspective. Africa Health. 26(3): $12-16$.

- Regensteiner JG., Bauer TA and Reusch JEB (2005) Rosiglitazone improves exercise capacity in individuals with Type 2 diabetes Diabetes Care 28: 2877 - 2883 . 